\title{
Developing Efficient Charging Schedule of Electrical Vehicles for Centralized Charging Station by Analyzing Impact on Distribution Network Due to EV Charging
}

\author{
Silvia Tasnim, Md. Jashim Uddin, Synthia Tahsin and Khairul Anam
}

\begin{abstract}
The penetration of Electric Vehicle (EV) on the distribution network has been increased worldwide and this has also boosted up the impacts on power system performance affecting voltage profile, voltage sensitivity factor, harmonics, overloading, increased grid loss resulting in reduced efficiency and power quality. A coordinated charging schedule can reduce this stress on the power grid and show significant improvement of network parameters. In this study, by simulating through Power Factory built-in MV/LV distribution test system, the impact of increasing EV on the distribution system has been analyzed and a simple approach of charging schedule for a centralized charging station has been proposed that will minimize the deteriorating impacts on connected distribution system due to EV charging.
\end{abstract}

Index Terms - Centralized charging station, EV charge scheduling, Reactive power margin, Total harmonic distortion, Voltage stability.

\section{INTRODUCTION}

Electric vehicles are a key technology to reduce air pollution in densely populated areas and a promising option to contribute to energy diversification and greenhouse gas emissions reduction. EV has better efficiency than internal combustion engine vehicles. Moreover, EV has reduced the direct and indirect cost of importing fossil fuel for many countries in the world.

An EV can act as a load to the distribution grid (charging), a mobile energy storage (ES) device, and a supplier of electricity to the grid (discharging). There are mainly three types of electric vehicles available worldwide i.e. Plug-inhybrid electric vehicle (PHEV), Hybrid electric vehicle (HEV), and Battery electric vehicle (BEV) [1], [2]. Electric vehicles, which expanded by an annual average of $60 \%$ in the 2014-19 period and there is a drastic change in their sales to potential customers.

Fig. 1 [3] shows that by 2019, number of EV had expanded to 7.2 million, $47 \%$ of which were in China. From 2018 to 2019, in this one year, the number of EVs increased to 2.1 million that exhibits $6 \%$ sales growth. In 2020, it is estimated that worldwide $3 \%$ of total car sales will be the sales of EVs.

With the increasing quality of EVs, there's the necessity to enhance charging infrastructures through mitigating system impact through correct scheduling. The infrastructure for electric-vehicle charging continues to expand. Fig. 2 [3]

Published on October 5, 2020

Silvia Tasnim, Ahsanullah University of Science and Technology, Bangladesh.

(corresponding e-mail: silvia121aust@ gmail.com)

Md. Jashim Uddin, Ahsanullah University of Science and Technology, Bangladesh. shows, in 2019, there were about 7.3 million chargers worldwide, of which about 6.5 million were private. But globally, the number of publicly accessible chargers (slow and fast) increased by $60 \%$ in 2019 compared with the previous year usage. $80 \%$ of publicly accessible fast chargers are in China for those with less opportunity for private charging at home. With support from governments, many countries have already partly adopted EVs in their transportation system systems.

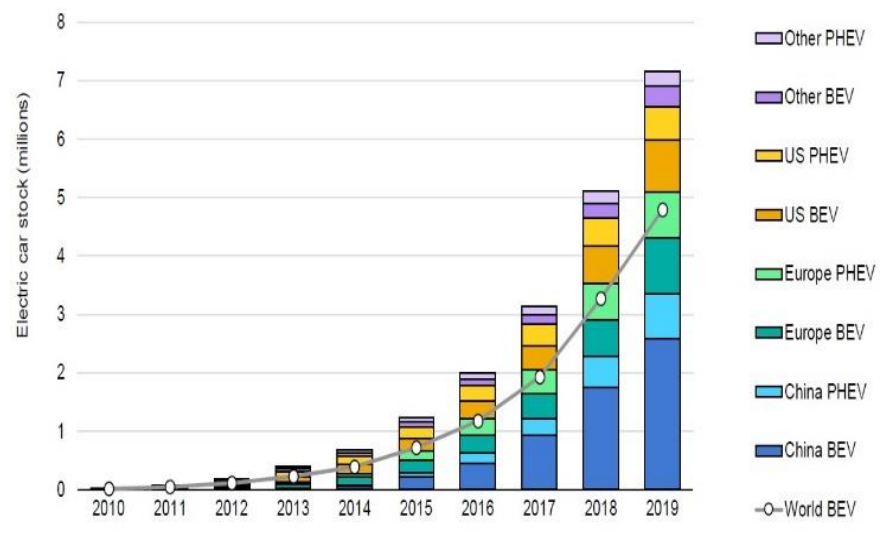

Fig. 1. Global electric car stock, 2010-19

So, a centralized charging station will expand this opportunity where the optimization of EV charging schedule is done centrally. Public charging stations currently installed worldwide, use both AC Level 2 and DC fast charging, respectively. [4]

With the growing number of EVs, however, there is a negative effect on the operating parameters of the power system induced by the EV charging loads. The high charging loads of the fast-charging stations (if fast chargers are used in centralized charging stations) results in increased peak load demand, reduced reserve margins voltage limit violations, phase imbalance, voltage instability, grid loss, transformers, and line loading, under-voltage, power quality issues, and harmonics problems. Furthermore, the penalty paid by the utility for the power system's deteriorating efficiency and performance cannot be overlooked [5], [6]. That's why additional system infrastructure needs to be developed. Uncoordinated EV charging, especially in long radial networks, can cause an excessive voltage drop. One solution to mitigate the impact of EVs on the grid is to

Synthia Tahsin, Ahsanullah University of Science and Technology, Bangladesh.

Khairul Anam, Ahsanullah University of Science and Technology, Bangladesh. 
schedule their charging profiles in a coordinated way by using surplus power in the lower demand hours.

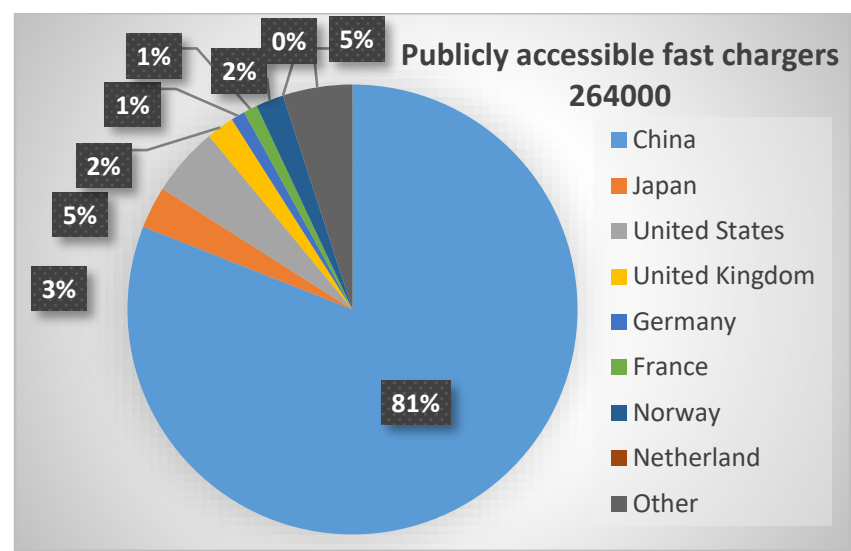

(a)

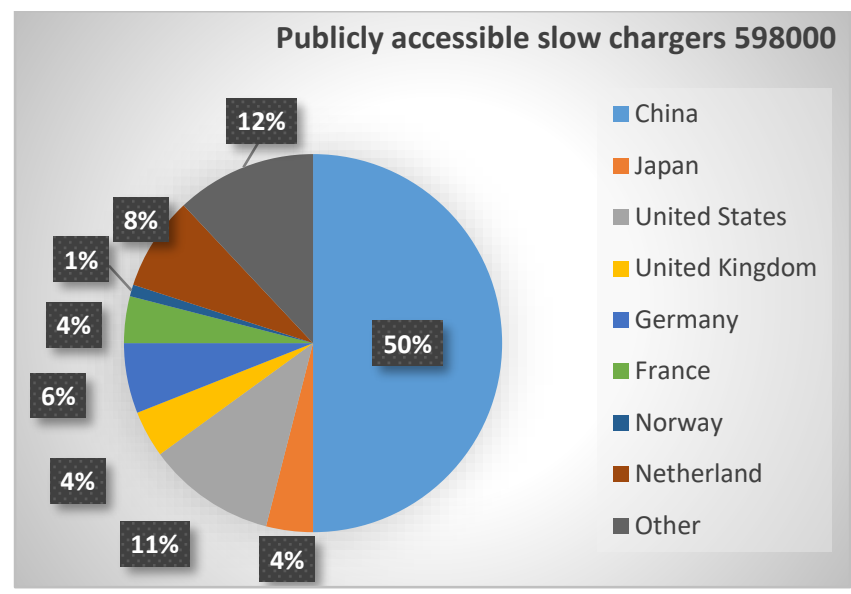

(b)

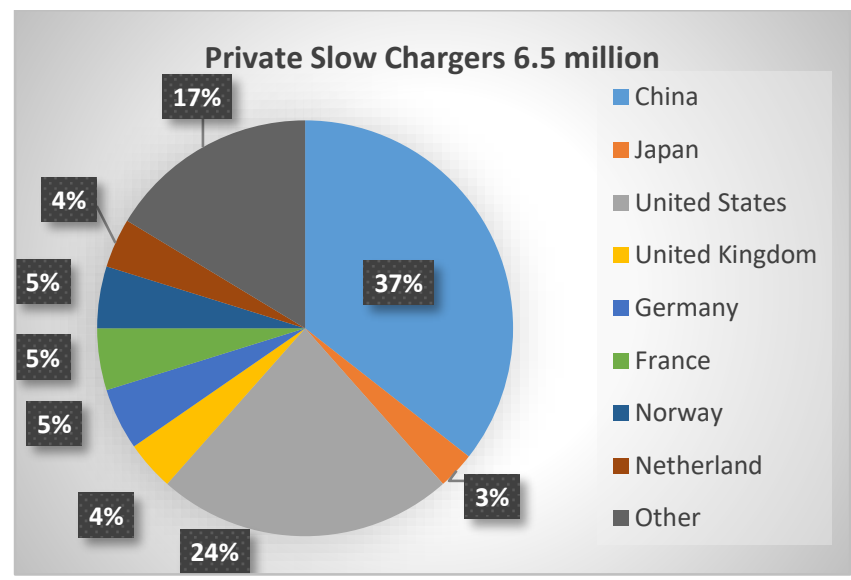

(c)

Fig. 2. (a) Publicly accessible fast chargers, (b) publicly accessible slow chargers, (c) private slow chargers by different countries worldwide, 2019.

Two types of interactions are possible between an EV and the power grid, namely, Grid to Vehicle (G2V) and Vehicle to Grid (V2G). In our study, centralized static charging with $\mathrm{G} 2 \mathrm{~V}$ unidirectional power flow is considered where EV's battery can be charged from the grid using stored electricity which is from external power sources. Without any significant adjustment to the new equipment or without any extra facilities being deployed, in the charging stations, all EVs can participate in the unidirectional power flow model [7].
The area has seen significant research activity in the last few years but our focus is to analyze the impact of EV loads on the system parameters while EVs are charged uncoordinated way and to justify a coordinated charging schedule to improve the impacts on the distribution network.

Section II shows while uncontrolled EV charging occurs, the distribution network faces many negative impacts. Then section III describes how to investigate these impacts on the distribution system due to EV charging by different indices and operational parameters. Section IV describes the methodology for finding the EV charging schedule. Section $\mathrm{V}$ presents the simulation results along with some discussions and explanations of the findings. Finally, section VI summarizes conclusions and future scope related to our work.

\section{IMPACT OF ELECTRIC VEHICLE CHARGING ON DISTRIBUTION NETWORK}

EVs have a major impact on the power gird \& distribution networks due to the huge power demand to recharge their batteries. Moderate to high penetration of EVs into the distribution grid will create some challenges in grid operation and management. Moreover, uncontrolled EV charging can cause a range of power network problems.

\section{A. Voltage Limit violation}

During the starting of EV charging, a high inrush current will be drawn for a few milliseconds which may deviate the voltage level, if this initial high current exceeds the acceptable limit. Voltage stability will be affected as the steady acceptable voltages at all the system buses under normal operating conditions is violated. Because of sudden disturbances, fault conditions, single or multiple contingencies, line overloading, or increase of loading conditions, will make the system unstable, and also voltage profile will be degraded [8]. So, EV loading will adversely affect the system voltage regulation.

\section{B. Reactive Power Issues}

The energy stored in the battery of EV in the form of DC, through AC-DC converter, conversion has to take place from $\mathrm{AC}$ to DC. The power factor of these converters should be greater than 0.95 to avoid insufficient reactive power flow. Reactive power flow in the line which is connected to the bus assumed as charging station has to be limited as it will impose a burden on the grid by increasing the total current of the system. Due to this increased current, the lifespan of the different components in the system will be affected adversely as heat losses also increase. [8], [9].

\section{Power System Losses}

The variable power system losses ( $I^{2} \mathrm{R}$ loss) increase, when the number of EV loads increases in the system for charging purposes. This non-linear relationship in the peak load period indicates that due to the high penetration of fast charging EVs, will contribute to the net increase in grid loss and phase imbalance in the distribution network [11].

\section{Transformer overloading and degradation}

Uncoordinated and increased number of EV will put stress on distribution transformers' lifespan. Transformers can be 
safely overloaded for short durations; however, the transformer life would be reduced if the operation is not balanced. Moreover, a higher number EV uncontrolled charging can start the early phase of transformer aging. The $\mathrm{EV}$ impact is dependent on the percentage increase in loading, relative to the load rating [12].

\section{E. Power quality issues}

EV battery chargers use power electronic devices to convert AC to DC power. This conversion process can cause total voltage and current harmonic distortion (THD) in the power system network. Increased harmonics result in additional power losses in the distribution transformer and reduces its life expectancy. Moreover, other distribution assets like Power Cables, protection devices may also lead to unexpected activity [8]-[10].

\section{F. Uncoordinated fast charging impact}

Many manufacturers will include a fast-charge connection in addition to Level 1 or Level 2 charging connections on most EVs, giving owners the option of quickly recharging their vehicles in commercial stations. Because of its high current demand and great load requirement by the charging system, the fast charge of EV requires more power leading to distribution loss. That's why proper coordination of charging is recommended for fast charging of EVs. When a certain percentage of EVs are allowed to get fast-charged in a scheduled time, total system loss will be reduced [13].

From the following Table 1 [14], it can be seen, that the typical fast charging power for different models of EV 50 $\mathrm{KW}$ on average. To initiate the charging schedule, this fast charging criterion is important considering EV battery capacity and EV models.

TABLE 1: DIFFERENT TYPES OF EV WITH CHARGING POWER

\begin{tabular}{ccccc}
\hline Model & $\begin{array}{c}\text { Battery } \\
\mathbf{k W h})\end{array}$ & $\begin{array}{c}\text { Slow } \\
\text { Charge } \\
\text { Power } \\
(\mathbf{k W})\end{array}$ & $\begin{array}{c}\text { Fast } \\
\text { Charge } \\
\text { Power } \\
(\mathbf{k W})\end{array}$ & $\begin{array}{c}\text { Consumption } \\
(\mathbf{k W h} / \mathbf{k m})\end{array}$ \\
\hline $\begin{array}{c}\text { Nissan Leaf } \\
\text { Tesla Model S }\end{array}$ & 40.00 & 6.60 & 50.00 & 0.1553 \\
70D & 75.00 & 7.40 & 50.00 & 0.2100 \\
BMW i3 & 33.20 & 7.40 & 50.00 & 0.1584 \\
Renault Zoe & 41.00 & 7.40 & - & 0.1460 \\
Renault Kangoo & 33.00 & 7.40 & - & 0.1926 \\
VW e-Golf & 24.20 & 7.20 & 40.00 & 0.1584 \\
Ford Focus & 33.50 & 6.60 & 50.00 & 0.1926 \\
Hyundai IONIQ & 33.50 & 6.60 & 50.00 & 0.1429 \\
\hline
\end{tabular}

\section{G. System imbalance}

EV loads are not evenly distributed on three phase power system while charging, so there is a possibility that load imbalance occurs among the phases. During which, there will be a difference in voltage and current in one phase compared to another. If the uncoordinated charging of EVs occurs, then voltage unbalance will cross the allowable limit [10].

\section{OPERATIONAL PARAMETERS AND INDICES TO ANALYZE SYSTEM IMPACT DUE TO EV CHARGING}

For analyzing the impact of EV load on distribution network some performance indices can be used to determine the proximity of the charging station bus of EV load to voltage collapse.

\section{A. Reactive Power Margin}

Reactive power margin indicates how further the loading on a particular bus can be increased before its loading limit reaches to the last value of acceptable limit and voltage collapse takes place. This index is used to determine voltage instability in a particular power system network. If the reactive power margin shows a higher value for a bus where EV load is connected and increased, that indicates that the system is quite stable is measured as a distance between the lowest MVAr point of Q-V curve and Voltage axis as shown in Fig. 3.[ 15], [16].

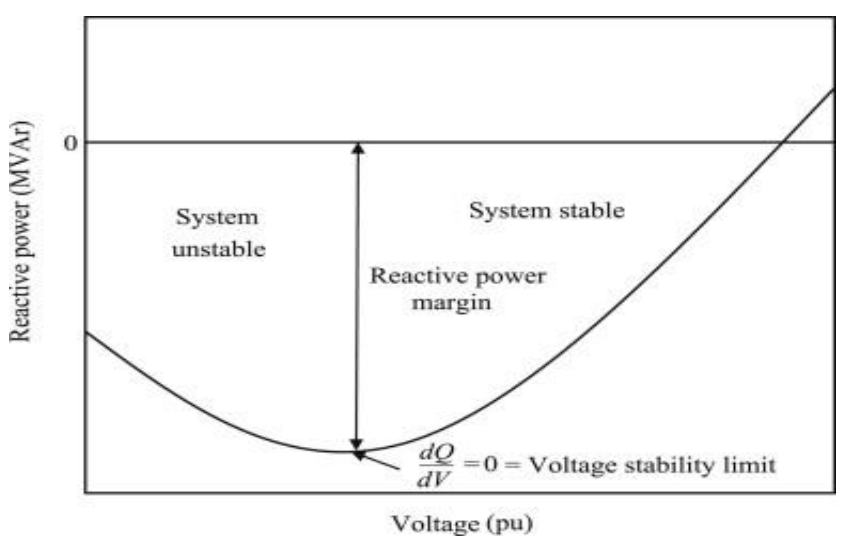

Fig. 3. Q-V curve and calculation of Reactive power margin.

\section{B. Voltage Sensitivity Factor (VSF)}

To determine whether the voltages of all the system buses along with the bus of EV loads are within acceptable limits ( $6 \%$ of their nominal value), voltage stability analysis is done based on the calculation of VSF from the PV curve. VSF is calculated by checking the system voltages concerning the change in loading. When the value of VSF becomes large, it indicates system insecurity due to unstable voltage control which may lead to severe voltage collapse. From $\mathrm{P}-\mathrm{V}$ curves $\mathrm{dv} / \mathrm{dp}$ index of active power sensitivity factor and form $\mathrm{Q}-\mathrm{V}$ curve $\mathrm{dv} / \mathrm{dq}$ index of reactive power sensitivity can be determined [17], [18].

\section{Total Harmonic distortion (THD)}

Total Harmonic distortion (THD) is introduced to measure the overall deviation of a periodic waveform from a perfect sine wave due to harmonics. Due to the nonlinear characteristics of EV loads, harmonic distortion originates in the power system network. According to IEEE 519- 2014 recommendations, shown in Table 2 [19] the standard for harmonics in North America, when the bus voltage is up to $1 \mathrm{KV}$, then the total harmonic distortion should be within an $8 \%$ limit to avoid voltage distortion and to maintain the power quality of that particular bus for normal system operation and this set limit of THD (\%) cannot be violated by utility and customers. For the fast 
charging of EV, THD (\%) will be higher than the slow charging of EVs.

TABLE 2: VOLTAGE DISTORTION LIMIT RECOMMENDED IN IEEE STANDARD 519-2014

\begin{tabular}{ccc}
\hline $\begin{array}{c}\text { Bus voltage V at } \\
\text { PCC }\end{array}$ & $\begin{array}{c}\text { Individual } \\
\text { harmonic }(\%)\end{array}$ & $\begin{array}{c}\text { Total harmonic } \\
\text { distortion THD (\%) }\end{array}$ \\
\hline$V \leq 1.0 \mathrm{kV}$ & 5.0 & 8.0 \\
$1 \mathrm{kV}<V \leq 69 \mathrm{kV}$ & 3.0 & 5.0 \\
$69 \mathrm{kV}<V \leq 161 \mathrm{kV}$ & 1.5 & 2.5 \\
$161 \mathrm{kV}<V$ & 1.0 & $1.5^{2}$ \\
\hline
\end{tabular}

\section{PROPOSED TECHNIQUE OF CHARGING SCHEDULE}

Charging schedule can be done by aggregating different sets of EVs for charging with different start times and durations such that grid constraints are maintained. Thus, determining the appropriate charging times of EVs that do not violate grid constraints while maintaining acceptable degrees of user satisfaction is a challenging problem.

To determine the most suitable charging schedule for the centralized charging strategy to minimize the influences on the power network, the overall procedure of the proposed approach can be summarized in the following steps:

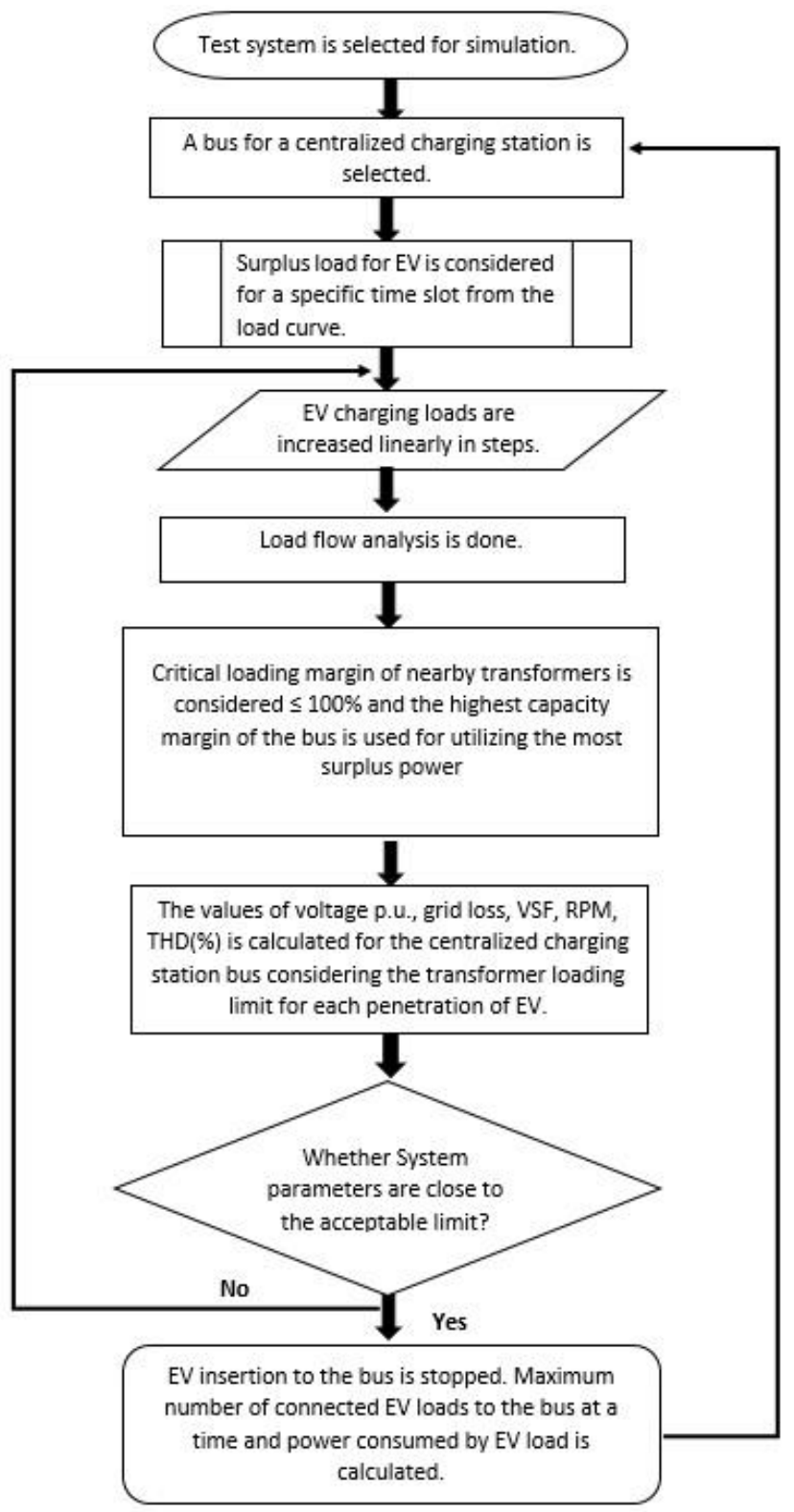

Fig. 4. Flowchart of the methodology.

\section{RESUlts AND ANALYSIS}

\section{A. Test system and analytics tools}

To validate the impact of Electrical vehicles, a study that has been made in Power Factory built in MV/LV distribution system is shown in Fig. 5. It's a distribution network with 20 buses. The simulation studies have been done by DigSILENT PoweFactory version 15.1.

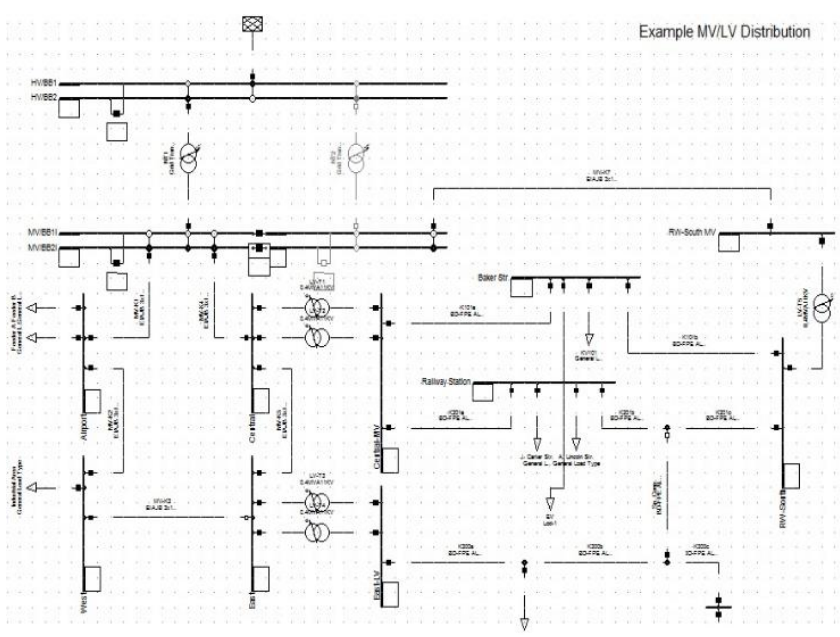

Fig. 5. MV/LV distribution System.

\section{B. Results}

1. Case study: Impact of EV load on the distribution system

The test system that has been used to find out the voltage profile with the increase of EV on baker str. buses. This bus is taken as the central charging station of EV having bus voltage of $0.4 \mathrm{kV}$ and connected to nearby transformers rated at $20 \mathrm{KV} / 0.4 \mathrm{KV}$ and rated capacity $400 \mathrm{KVA}$. To determine the voltage with the increase of EV, several load flows analyses have been done. EV load has been increased linearly to show that due to uncoordinated charging of EVs resulted in voltage imbalance and grid loss. Based on the data that a fast EV charger modeled that consumes $50 \mathrm{~kW}$ energy and the complete evacuation done by this way for all the cases. Here, we assume the load power factor is 1 .

The process of obtaining P-V Curves involves a series of load flow solutions by increasing the EV load (MW) and as a result variation of voltage at Baker Str. bus mentioned here. The real power transfer is incremented as at constant power factor and the bus voltages are monitored. Curves are plotted for Baker Str. bus.

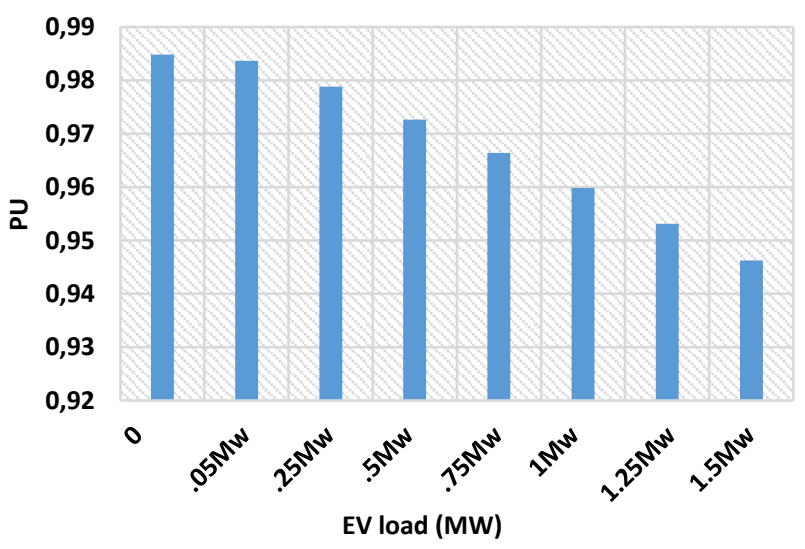

Fig. 6. Voltage p.u. Vs EV Load. 
In Fig. 6 it's shown the bar chart of p.u. value of Baker St. bus for different EV loading factor. With the increase of EV load, Baker Str. bus pu has been decreased. For better analysis, it considers that 0.95 is the healthy bus state so that it could not affect the system.

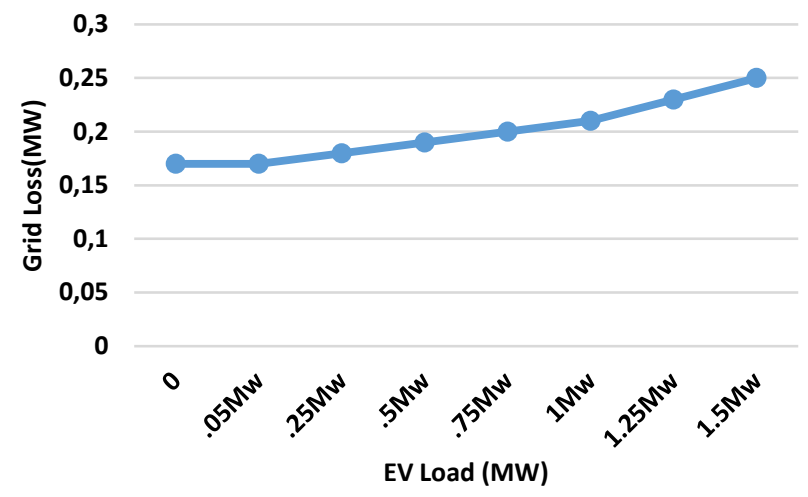

Fig. 7. Grid Loss Vs EV load.

In Fig. 7, it illustrates that with the gradual expansion of electric vehicle load what is the impact of grid loss changed. From the curve, it's clear that with the increase of EV load the power loss of the grid increased compared to when no EV was connected (base case).

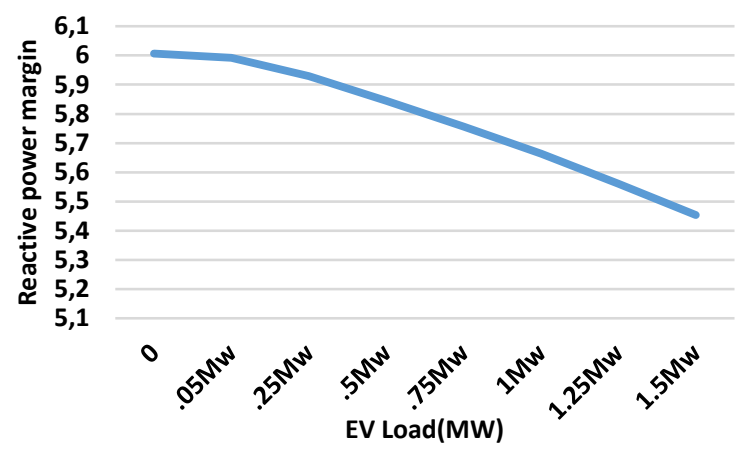

Fig. 8. Reactive power margin Vs EV load.

Fig. 8 shows that the reactive power margin of the of Baker Str. bus with the increase of EV load. With the increase of EV load of the system reactive power margin of the bus decreased. And it proves that this selected central charging station bus is sensitive to reactive power margin.

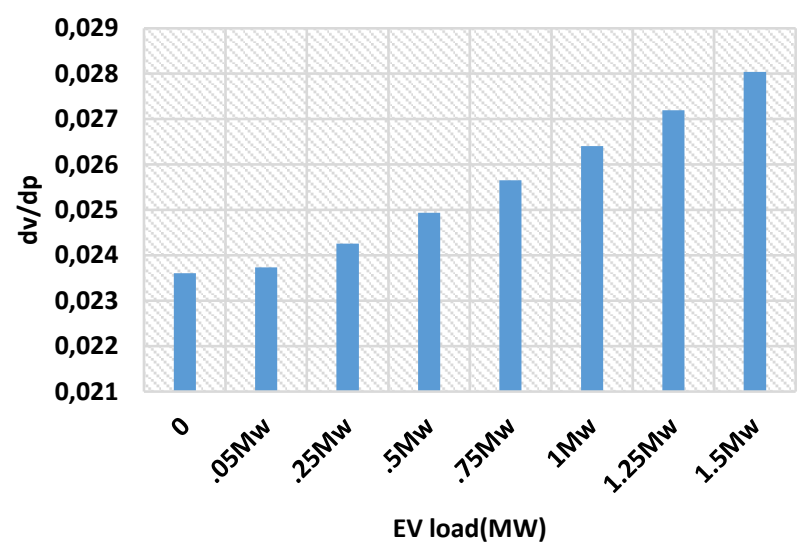

Fig. 9. Active power sensitivity factor Vs EV load.
In Fig. 9 it's shown that the impact of active power sensitivity factor with the variation of EV load. As EV load increases the impact of active power sensitivity factor increases. For more increase of EV load in this bus, will lead to a high VSF value that for a small change of EV loading, there will be a considerable voltage drop.

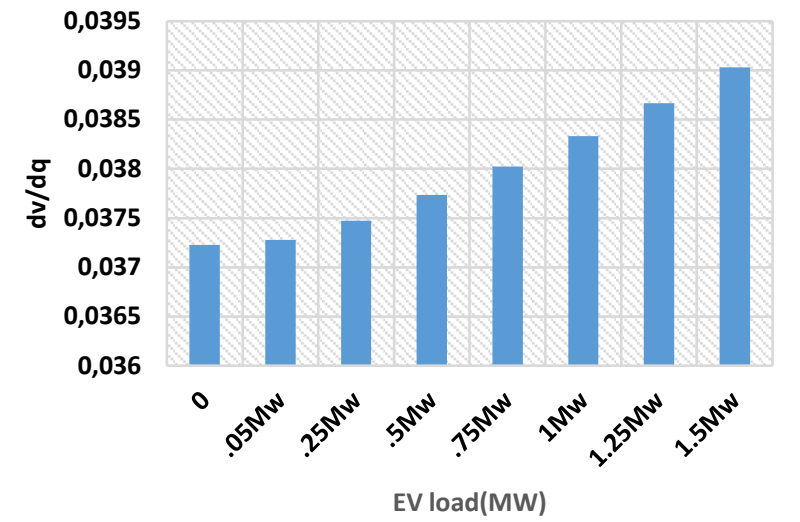

Fig. 10. Reactive power sensitivity factor Vs EV load.

In Fig. 10 it's shown that the impact the reactive power sensitivity factor vs EV load. Reactive power sensitivity factor also shows great impact with the variation of EV load.

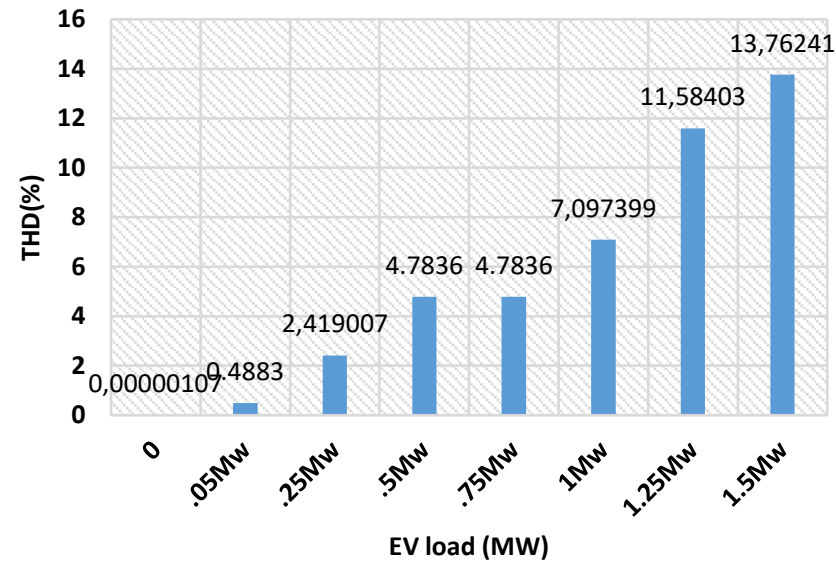

Fig. 11. Total Harmonic Distortion Vs EV load.

In Fig. 11 it's shown the effect of THD (\%) of Baker Str. Bus with the growth of EV load. The impact of EV load in the system is so prominent that with the expansion of EV load in the system total harmonic distortion increased rapidly and also violates its predefined limit after inserting a certain number of EVs.

2. Proposed Strategies of charging schedule

The daily normal load profile without EV charging load for a definite area is shown below in Fig.12 [20]. 
TABLE 3: EV LOAD SCHEDULING (CONSIDERING SYSTEM IMPACT)

\begin{tabular}{|c|c|c|c|c|c|c|c|c|c|c|}
\hline $\begin{array}{l}\text { Scheduled } \\
\text { Time }\end{array}$ & $\begin{array}{l}\text { Regular } \\
\text { load }\end{array}$ & $\begin{array}{c}\text { EV load (can be } \\
\text { connected) Surplus }\end{array}$ & $\begin{array}{l}\text { Max no. of } \\
\text { EV load at a } \\
\text { time }\end{array}$ & $\begin{array}{c}\text { EV } \\
\text { Load } \\
(\mathrm{MW})\end{array}$ & $\begin{array}{l}\text { Voltage } \\
\text { (pu) }\end{array}$ & $\begin{array}{l}\text { Grid } \\
\text { Loss } \\
(\mathrm{MW})\end{array}$ & dv/dp & $d v / d q$ & $\begin{array}{c}\text { Reactive } \\
\text { power } \\
\text { margin }\end{array}$ & $\begin{array}{c}\text { THD } \\
(\%)\end{array}$ \\
\hline $5 \mathrm{pm}-10 \mathrm{pm}$ & $70 \%$ & $30 \%$ & 10 & 0.50 & 0.96 & 0.2 & 0.025879 & 0.038717 & 5.56907 & 4.816287 \\
\hline $10 \mathrm{pm}-5 \mathrm{am}$ & $40 \%$ & $60 \%$ & 20 & 1 & 0.96 & 0.2 & 0.026073 & 0.038022 & 5.71785 & 8.066067 \\
\hline $8 \mathrm{am}-12 \mathrm{pm}$ & $75 \%$ & $25 \%$ & 9 & 0.45 & 0.96 & 0.2 & 0.025926 & 0.038861 & 5.52601 & 4.350801 \\
\hline
\end{tabular}

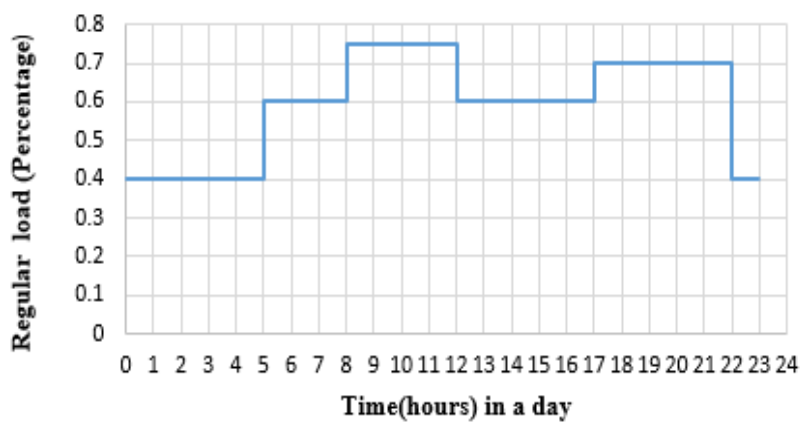

Fig. 12. Regular Load Profile (without EV).

In Fig. 13 the length of the basic period is set to be $24 \mathrm{~h}$, which is in accordance with the one-day cycle. The basic period is divided into several time slots equivalently, and during each time slot, the scheduled charging of EV load will vary. In peak hour minimum numbers of EV will take charge and in off-peak hours' maximum numbers of EV could take charge in the charging station. To reduce the impact of the bus or nearby transformer the scheduling is done in such a way that nearby transformers won't be overloaded, bus p.u. won't decrease less than $5 \%$ and total harmonic distortion won't cross $8 \%$ limit.

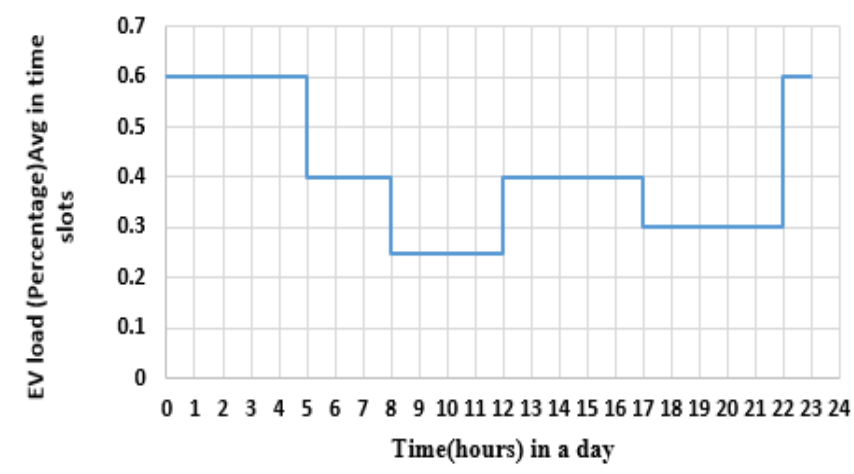

Fig. 13. Proposed Charging Schedule [EV load (\%)] at a time.

In Fig.14 it's showing the percentage of EV load connected to the system in a different time schedule.

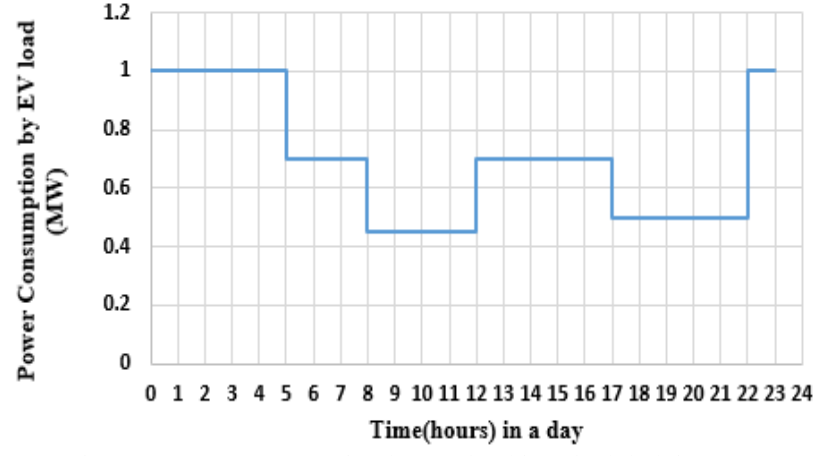

Fig. 14. Power consumption by EV load in scheduled time.

In Table 3, it's showing that the scheduling of EV load and its impact results on the system. From the above charging schedule it is observed that, as each EV load will take $50 \mathrm{KW}$ for fast charging, from $12 \mathrm{pm}-5 \mathrm{pm}$, the charging station has the capability to charge 14 EVs with a total load of $0.70 \mathrm{MW}$ at a time maintaining all the aforementioned system parameters. According to load curve, $8 \mathrm{am}-12 \mathrm{pm}$ is the peak hour where only $9 \mathrm{EV}$ loads can be charged at a time whereas in the off-peak hour of $10 \mathrm{pm}-$ 5 am due to lower normal load the maximum number of EV loads at a time can be connected to charging station is 20 which required nearly $1 \mathrm{MW}$ power consumption by EV load.

Though the load is varied with the variation of time but the $\mathrm{pu}$ of the system remains within limit of $0.95 \mathrm{pu}-$ $1.05 \mathrm{pu}$. The pu value of the bus is almost constant. The system power grid loss also remains the same limit nearly of $0.2 \mathrm{MW}$. The same effect is noticeable for active power and reactive power sensitivity factor and reactive power margin. The only factor which is not remaining constant and which had a great impact on the system is total harmonic distortion, though after the effective scheduling the percentage of total harmonic distortion (THD)of the bus remains within the permissible limit of $8 \%$, which is good for the system. As only the surplus power is considered, maintaining the maximum utilization of the system capacity with minimum impact due to EV charging, the limit of connected EV for charging in a definite period is considered to keep the whole system healthy.

\section{CONCLUSIONS}

If EV loads are connected to power grid for their battery charging purpose, it will impose tremendous impact on daily residential load curve. Uncoordinated random charging of EVs may lead to unsatisfactory effects on normal operation of distribution system. In this paper, a coordinated charging 
schedule with a centralized EVs charging strategy for peak and off-peak hours is proposed to reduce the voltage deviation, power loss, and harmonics generation due to $\mathrm{EV}$ loads by flattening out the peak demand. Here, we conclude grid to vehicles $(\mathrm{G} 2 \mathrm{~V})$ charging impact and optimum efficient charging scheduling considering maximum utilization of available grid power. This will show the maximum number of EV load in scheduled time.

\section{ACKNOWLEDGEMENT}

We are grateful to the department of EEE, Ahsanullah University of Science and Technology for providing the necessary support and instruction to complete this research.

\section{REFERENCES}

[1] J. C. Mukherjee and A. Gupta, "A Review of Charge Scheduling of Electric Vehicles in Smart Grid," in IEEE Systems Journal, vol. 9, no. 4, pp. 1541-1553, Dec. 2015, doi: 10.1109/JSYST.2014.2356559.

[2] Damiano, A.; Marongiu, I.; Porru, M.; Serpi, A. Electric Vehicle Energy Storage Management for Renewable Energy Sources Exploitation. In Proceedings of the 2012 IEEE International Electric Vehicle Conference (IEVC 2012), Greenville, SC, USA, 4-8 March 2012; pp. 1-8.

[3] International Energy Agency. Global EV Outlook 2020; Technical Report; International Energy Agency: Paris, France, 2020. Available online: https://webstore.iea.org/global-ev-outlook-2020 (accessed on 28 Aug 2020)

[4] Sundstrom, O.; Binding, C. Optimization Methods to Plan the Charging of Electric Vehicle Fleets. ACEEE Int. J. Commun. 2010, 1, $45-50$.

[5] Deb, S.; Tammi, K.; Kalita, K.; Mahanta, P. Impact of Electric Vehicle Charging Station Load on Distribution Network. Energies 2018, 11, 178.

[6] Dharmakeerthi, C.H.; Mithulananthan, N.; Saha, T.K. Impact of electric vehicle fast charging on power system voltage stability. Int. J. Electr. Power Energy Syst. 2014, 57, 241-249.

[7] O. Sundstrom and C. Binding, "Flexible Charging Optimization for Electric Vehicles Considering Distribution Grid Constraints," in IEEE Transactions on Smart Grid, vol. 3, no. 1, pp. 26-37, March 2012, doi: 10.1109/TSG.2011.2168431.

[8] Study Report: Impact Assessment of Large Scale Integration of EV Charging Infrastructure to Distribution Grid. Available online https://thecityfixlearn.org/webinar/impact-electric-vehicle-evcharging-local-grid (accessed on 22 Aug 2020).

[9] Report of European Distribution System Operators for Smart Grid on "Smart charging: integrating a large widespread of electric cars in electricity distribution grids," March 2018.

[10] Robert Bass, Nicole Zimmerman, "Impacts of Electric Vehicle Charging on Electric Power Distribution Systems", Electrical and Computer Engineering Faculty Publications and Presentations, Sep 2013.

[11] ]F. J. Soares, J. A. P. Lopes and P. M. R. Almeida, "A Monte Carlo method to evaluate electric vehicles impacts in distribution networks," (2010 IEEE Conference on Innovative Technologies for an Efficient and Reliable Electricity Supply, Sept 2010, pp. 365-372).

[12] Wetzer, Jos. "Operation of transformers: Impact of harmonic loading on transformer losses." Transformers Magazine 5, no. 1 (2018): 74 79.

[13] M. Singh, I. Kar and P. Kumar, "Influence of EV on grid power quality and optimizing the charging schedule to mitigate voltage imbalance and reduce power loss," Proceedings of 14th International Power Electronics and Motion Control Conference EPE-PEMC 2010, Ohrid, 2010, pp. T2-196-T2-203, doi: 10.1109/EPEPEMC.2010.5606657.

[14] Canizes, B.; Soares, J.; Costa, A.; Pinto, T.; Lezama, F.; Novais, P.; Vale, Z. Electric Vehicles' User Charging Behaviour Simulator for a Smart City. Energies 2019, 12, 1470.

[15] Tareq Aziz, T. K. Saha, N. Mithulananthan "Distributed Generators Placement for Loadability Enhancement based on Reactive PowerMargin" p. 740-741.

[16] Roy, N. K., Pota, H. R., \& Hossain, M. J. (2013). Reactive power management of distribution networks with wind generation for improving voltage stability. Renewable Energy, 58, 85-94 doi:10.1016/j.renene.2013.02.030.

[17] Rahman, M. M.; Barua, S.; Zohora, S. T.; Hasan, K.; Aziz, T. Voltage sensitivity based site selection for PHEV charging station in commercial distribution system. In Proceedings of the Asia Pacific Power and Energy Engineering Conference, Hong Kong, China, 8-11 December 2013; pp. 1-6.

[18] Deb, S., Tammi, K., Kalita, K., \& Mahanta, P. (2018). Impact of Electric Vehicle Charging Station Load on Distribution Network. Energies, 11(1), [178]. DOI: 10.3390/en11010178.

[19] IEEE Standard 519-2014, IEEE Recommended Practice and Requirements for Harmonic Control in Electric Power Systems, (Revision of IEEE Standard 519-1992) (IEEE, 2014), pp. 1-29.

[20] Hu, Z., Zhan, K., Zhang, H., \& Song, Y. (2016). Pricing mechanisms design for guiding electric vehicle charging to fill load valley. Applied Energy, 178, 155-163. 